\title{
Epilepsiechirurgie voor Focale Corticale Dysplasie
}

Op woensdag 25 november 2020 promoveerde Tim Veersema aan de Universiteit van Utrecht op het proefschrift 'Epilepsy Surgery for Focal Cortical Dysplasia: Clinicopathological correlates and advances in neuroimaging'? In dit proefschrift onderzoekt hij de relatie tussen preoperatieve beeldvorming en postoperatieve histopathologische diagnose. Het uiteindelijke doel is om preoperatief beter te kunnen inschatten wat die diagnose is, omdat dit waarschijnlijk iets zegt over de postoperatieve cognitie en kans op aanvalsvrijheid.

\section{Waarom}

Ongeveer een kwart van de patiënten die geopereerd worden voor epilepsie heeft een focale corticale dysplasie (FCD). In 201 ir heeft de International League against Epilepsy (ILAE) een nieuwe classificatie van deze aandoening uitgebracht, waarbij een onderverdeling is gemaakt in type I en II op basis van de cytoarchitectuur, en in een type III waarbij er een associatie moet zijn met een andere aandoening. Hele subtiele afwijkingen worden geclassificeerd als mild malformations of cortical development (mMCD). Grofweg $50 \%$ van de FCD-patiënten wordt na operatie aanvalsvrij en kan stoppen met medicatie. Dit percentage lijkt gecorreleerd met het type FCD, maar dit is voor de nieuwe classificatie niet goed onderzocht. Daarnaast lijkt het type FCD geassocieerd met de cognitieve uitkomst na operatie. Deze twee kwesties werden onderzocht. Vanwege de potentiële klinische relevantie van de histopathologische subtypering van FCD werd daarnaast onderzocht of $7 \mathrm{~T}$ MRI en geavanceerde beeldanalysetechnieken kunnen bijdragen aan preoperatieve bepaling daarvan.

\section{Hoe}

In retrospectieve cohortstudies werd onderzocht welke histopathologische factoren samenhingen met postoperatieve aanvalsvrijheid en cognitie, en wat de opbrengst is van een $7 \mathrm{~T}$ MRI bij patiënten bij wie een FCD vermoed werd, maar niet was gevonden op conventionele MRI. In een aparte studie werd beschreven wat specifieke $7 \mathrm{~T}$ kenmerken zijn op $\mathrm{T}_{2}{ }^{*}$ gewogen sequenties van subtiele laesies die op lager veld niet ontdekt waren (figuur I). De beschreven afwijkingen werden vervolgens gekarakteriseerd in een histopathologische studie. Hiernaast liep ook nog een prospectieve studie waarin in vivo preoperatieve $7 \mathrm{~T}$ MRI werd gecorreleerd aan hetzelfde gereseceerde weefsel gescand op $7 \mathrm{~T}$ en de $3 \mathrm{D}$-histopathologie daarvan.

\section{Resultaat}

In een serie van 88 patiënten die in Utrecht zijn geopereerd werd in vergelijking met internationale literatuur een relatief hoog percentage mMCD gevonden (35\%) en een relatief laag percentage FCD I ( $9 \%)$. De patiënten met FCD II (56\%) hadden een hoge kans op aanvalsvrijheid (IIA $53 \%$, IIB 66\%) (Veersema et al., 2018). De patiënten met een mMCD scoren aanmerkelijk slechter (32\%) (Veersema et al., 2018). In een groep van 42 kinderen werden zowel voor als na epilepsiechirurgie cognitieve testen gedaan. Ongeveer de helft daarvan had een cognitieve beperking voor operatie (ICQ/DQ < 70) en dat gold voor alle patiënten met een FCD type I (Veersema et al., 2019a). Kinderen met MMCD en FCD type II scoren preoperatief cognitief aanmerkelijk beter (Veersema et al., 2019a). 43\% van de kinderen liet na operatie een klinisch relevante stijging van de intelligentie zien ( $>7 \mathrm{IQ} / \mathrm{DQ}$ punten), $46 \%$ was stabiel en II \% ging achteruit. Er kon geen relatie gelegd worden met het subtype FCD.

In 40 achtereenvolgende patiënten waarbij een $7 \mathrm{~T}$ MRI was verricht, werd bij negen patiënten ( $23 \%$ ) een nieuwe klinisch relevante afwijking geïdentificeerd. Zes van deze patiënten waren geopereerd ten tijde van de studie en allemaal bleken ze een dysplasie te hebben (tweemaal type IIA, eenmaal type IIB, driemaal mMCD). Bij de beoordeling van de scans viel op dat bij deze laesies de afwijking vooral zichtbaar was in sterk $\mathrm{T}_{2} \star$ gewogen sequenties. In vier van de zes patiënten, waren er diep hypointense gebieden met een vertakkende, deels tortueuze configuratie, suggestief voor toegenomen veneuze vaatstructuren in de sulci en in mindere mate ook in het hersenparenchym (zie figuur I) (Veersema et al., 20Igb). De aanvullende kwantitatieve immunohistochemische analyse van microvasculaire densiteit en ontsteking in hersenweefsel van 97 dysplasiepatiënten liet een hogere vaatdichtheid in de hersenschors

${ }^{1}$ Promotoren: Professor K.P.J. Braun, kinderneuroloog UMC Utrecht, Professor E.M.A. Aronica, neuropatholoog Amsterdam UMC, Co-promotoren: Dr. P. van Eijsden, neurochirurg UMC Utrecht, Dr. C.H. Ferrier, klinisch neurofysioloog UMC Utrecht 

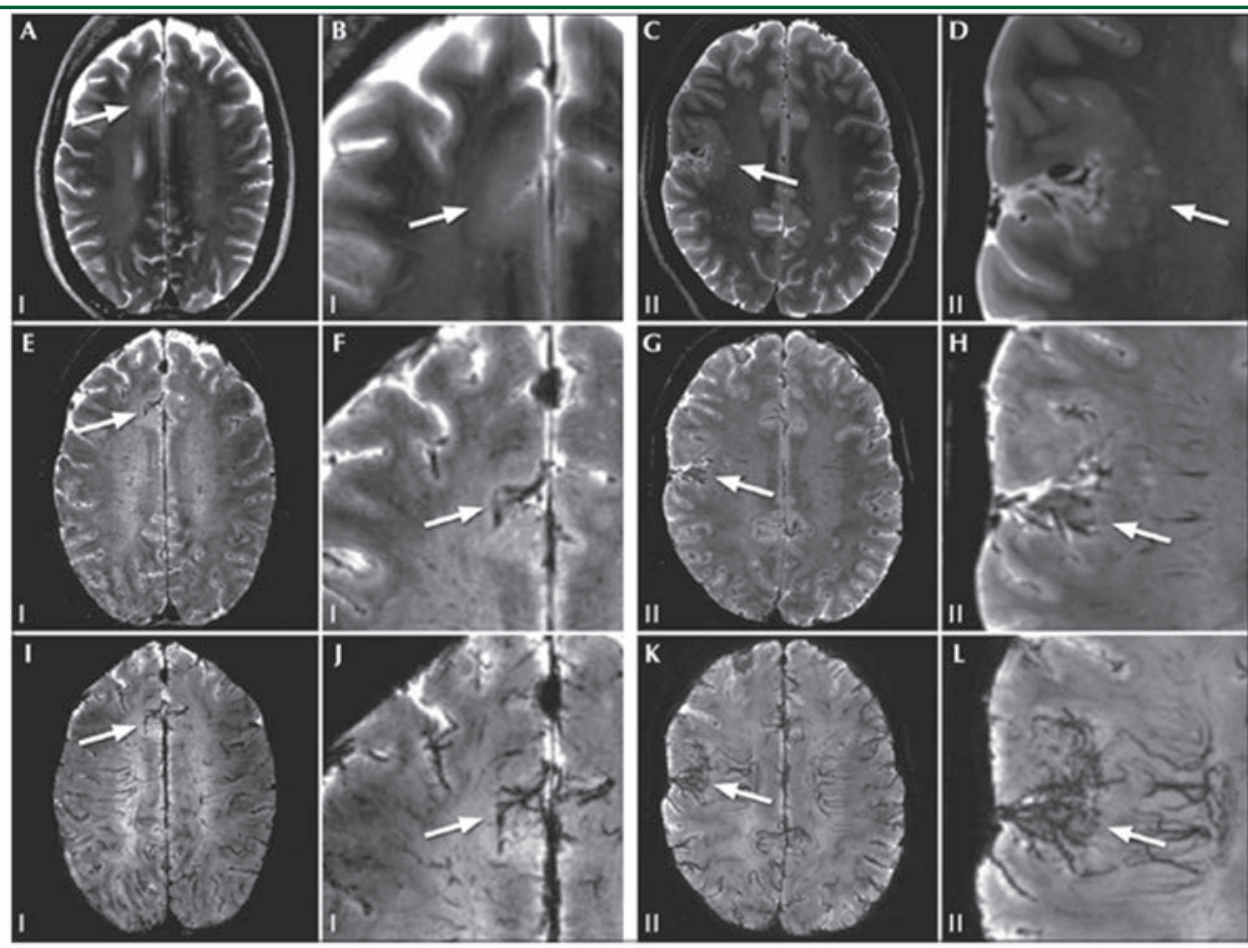

Figuur 1 MRI afwijkingen op 7 T MRI bij MRI negatieve patiënten en histologisch bevestigde FCD: 7T T2 (A-D), T2* (E-H) and T2* minimum intensity projection (I-L). Laesies zijn uitvergroot in (B), (D), (F), (H), (J) and (L). Patiënt I; FCD ILAE type IIB (A, B, E, F, I, J). Patiënt II; FCD ILAE type IB (C, D, G, H, K, L). De witte pijlen wijzen op gebieden met een tortueuze hypo-intense afwijking die colokaliseert met de laesie.

en witte stof in FCD zien ten opzichte van het omliggende weefsel (Veersema et al., 2orgb). Er was echter geen significant verschil in vaatdichtheid tussen patiënten en de controlegroep zonder epilepsie.

Eerder werd al benadrukt wat het belang is van preoperatieve identificatie en bepaling van de begrenzing van een afwijking en van een accurate histopathologische diagnose. Kandidaten voor epilepsiechirurgie ondergingen een $7 \mathrm{~T}$ MRI-scan. Het weefsel dat vervolgens tijdens een operatie werd verkregen, werd gescand op de $7 \mathrm{~T}$ MRI, waarbij 3 D-resoluties tot 0,2 $\mathrm{mm}$ werden behaald. Verdere vooruitgang en aanvullende kennis kan worden verworven door analysehulpmiddelen die het mogelijk maken de $7 \mathrm{~T}$ MRI-beelden met histologische bevindingen te associëren (Veersema et al, 20I6; 20I7). Er is software ontwikkeld die de in vivo en ex vivo MRI-beelden kon co-registreren met histologische coupes. Dit maakt het mogelijk om FCD's op een pixel by pixel basis te karakteriseren op verschillende hoogveld MRI-parameters en een serie aan (immuno)histologische kenmerken.

\section{Belang voor de epileptologie}

Chirurgische behandeling van medicatie-resistente epilepsie bij patiënten met mMCD of FCD is de enige therapie met kans op aanvalsvrijheid en kent een hoge succeskans met lage risico's. Dit proefschrift toont aan dat de nieuwe FCD-classificatie relevante klinische profielen weet te on- derscheiden. De verschillende subtypes hebben verschillende kansen op aanvalsvrijheid na operatie en er is een verband met cognitie. Er is over mMCD als separate entiteit nog een debat gaande. Nieuwe inzichten en bijvoorbeeld inzet van genetische en moleculaire typeringen zouden de classificatie verder kunnen doen ontwikkelen.

Met bovenstaand resultaat in handen lijkt preoperatieve karakterisering van het FCD-type relevant. Dit proefschrift toont aan dat 7 T MRI in staat is om bij ongeveer een kwart van de patiënten die mogelijk een nog niet gedetecteerde FCD hebben, er een aan te tonen. Het lijkt dus verstandig dit ook aan te bieden bij MRI-negatieve patiënten met een focale epilepsie die in aanmerking zouden kunnen komen voor een resectie indien een laesie wordt aangetoond. Tevens is een nieuw MRI-fenomeen beschreven op $\mathrm{T}_{2}{ }^{{ }^{*}}$ gewogen scans. De histopathologische karakterisering hiervan heeft geen eenduidig resultaat opgeleverd, maar er lijkt bij FCD's sprake te zijn van toegenomen vasculariteit die zou kunnen bijdragen aan dit verschijnsel. Een verdere stap op weg naar preoperatieve karakterisering van FCD type is gezet door een protocol te realiseren waarbinnen co-registratie mogelijk is van preoperatieve MRI-beelden met het uitgenomen weefsel. Toekomstig onderzoek zal moeten aantonen welke relaties er zijn tussen MRI- en histopathologische-karakteristieken. Dit baant de weg voor automatische laesiedetectie in MRI-beelden van patiënten met predictie op FCD en FCD-type. 
Referenties

Veersema TJ, van Eijsden P, Gosselaar PH, et al. (20I6). 7 Tesla T2*-weighted MRI as a tool to improve detection of focal cortical dysplasia. Epileptic Disord.

I; I8(3):3I5-23.

Veersema TJ, Ferrier CH, van Eijsden P, et al. (2017). Seven tesla MRI improves detection of focal cortical dysplasia in patients with refractory focal epilepsy. Epilepsia Open. I0;2(2):I62-I7I.

Veersema TJ, Swampillai B, Ferrier CH, et al. (2018). Long-term seizure outcome after epilepsy surgery in patients with mild malformation of cortical develop- ment and focal cortical dysplasia. Epilepsia Open

I3;4(I):I70-I75.

Veersema TJ, van Schooneveld MMJ, Ferrier CH, et al.

(2orga). Cognitive functioning after epilepsy surgery in

children with mild malformation of cortical develop-

ment and focal cortical dysplasia. Epilepsy Behav.

94:209-2I5.

Veersema TJ, de Neef A, van Scheppingen J, et al. (20Igb).

Hanges in vascular density in resected tissue of 97

patients with mild malformation of cortical develop-

ment, focal cortical dysplasia or TSC-related cortical

tubers. Int J Dev Neurosci. 79:96-I04.

Door: Marieke Reuvekamp (mreuvekamp@sein.nl), psychologie, Stichting Epilepsie Instellingen Nederland, Zwolle

\section{Frontale epilepsie; impact op cognitie en gedrag bij kinderen}

Lydia van den Berg promoveerde op I9 april 202I aan de Rijksuniversiteit Groningen op het proefschrift Epilepsy out of control; when frontal lobe epilepsy becomes more than seizures ${ }^{I}$. In haar proefschrift is er vooral aandacht voor executieve functies bij kinderen met frontale epilepsie. Welke gedrags- en cognitieve problemen ondervinden deze kinderen en verschilt de rapportage hierover van leerkrachten en ouders?

Kinderen met frontale epilepsie (FLE) kunnen gedrags- en leerproblemen ontwikkelen, maar meer specifiek kan er sprake zijn van executieve functieproblemen. Executieve functies (EF) vallen het best te omschrijven als functies die je hele doen en laten aansturen en controleren. Problemen met executieve functies betreffen bijvoorbeeld de mate waarin gedrag kan worden geremd en de mate waarin er geschakeld kan worden tussen situaties. Hoewel er steeds meer kennis is over de onderliggende neuroanatomie en de specifieke cognitieve beperkingen, blijft de impact van FLE op het dagelijks functioneren bij kinderen met deze vorm van epilepsie onduidelijk.

\section{Doel en opzet}

Het doel van het onderzoek was om meer inzicht te verwerven in de gevolgen van FLE op executieve functies en op het gedrag en leren. Er werden 32 kinderen tussen 7 en I2 jaar geïncludeerd met de diagnose FLE (IQ>70), die door de kinderneurologen van Stichting Epilepsie Instellingen Nederland (SEIN Zwolle) waren verwezen voor neuropsychologisch onderzoek. Alle kinderen kregen een uitgebreid neuropsychologisch onderzoek en ouders en leerkrachten vulden meerdere (gedrags-) vragenlijsten in.

${ }^{1}$ Promotor profdr J.J. van der Meere, co-promotor dr A.W. de Weerd

\section{Gedragsproblemen}

Van den Berg (2018) toont aan dat zowel ouders als leerkrachten bij ongeveer eenderde van de onderzoeksgroep gedrags- en problemen met EF rapporteren. Daarbij bleek dat kinderen die problemen hebben met EF ook meer gedragsproblemen tonen. Dit werd nog niet eerder onderzocht bij kinderen met epilepsie. Er blijkt een sterke samenhang te zijn tussen de rapportage van ouders en leerkrachten, zij blijken veelal tegen dezelfde problemen aan te lopen. Verder komt naar voren dat angst en depressie relatief weinig gezien worden bij deze groep kinderen met FLE. Bij andere vormen van epilepsie zijn dit juist de meest gerapporteerde problemen (Smith, 20I6). De problemen die bij kinderen met FLE worden gezien zijn vooral externaliserende gedragsproblemen, zoals gedragsregulatieproblemen. Ouders geven aan meer last te ervaren in het opvoeden van hun kinderen als er meer (externaliserende) gedragsproblemen gerapporteerd worden. Overigens valt de last die ouders ervaren van het opvoeden van kinderen met FLE in deze onderzoeksgroep over het algemeen mee (van den Berg et al., 20Iga). Ouders met kinderen die al langer epilepsie hebben (meer dan vijf jaar) hebben de meeste moeite met het opvoeden van deze kinderen. Een onverwachte bevinding is verder dat ongeveer de helft van de ouders niet consistent is in hun antwoorden. Een 